УДК 332.012.23:330.101.22

08.00.00 Экономические науки

ТЕОРИЯ ЗЕМЕЛЬНОЙ РЕНТЫ КАК
МЕТОДОЛОГИЧЕСКАЯ ОСНОВА
ИНСТИТУЦИОНЛЬНОГО
РЕГУЛИРОВАНИЯ ЗЕМЕЛЬНЫХ
ОТНОШЕНИЙ: ИСТОРИЧЕСКИЙ ЭКСКУРС

Барсукова Галина Николаевна

к.э.н., профессор кафедры землеустройства и земельного кадастра

Кубанский государственный аграрный университет им. И.Т. Трубилина, Краснодар, Россия

Рассмотрено развитие теории земельной ренты, показаны исторические этапы формирования института земельной ренты в ретроспективе. Приведены взгляды на определение рентообразующих факторов и формирование механизма земельной ренты основателей теории земельной ренты - физиократов, У. Петти, Д. Рикардо, А. Смита,

К.Маркса, А. Маршалла и других авторов. В результате исследования различных концепций, взглядов, методик развития институтов земельной собственности, земельной ренты и земельных платежей сделан вывод, что земельная рента выступает как экономическая форма реализации земельной собственности; теория земельной ренты представляет собой методологическую основу определения и развития всех институтов экономического регулирования земельных отношений; в рыночной экономике объективные рентные отношения должны проявляться в земельном налоге, в арендной плате за землю, цене земли. Определены дискуссионные положения современной трактовки земельной ренты - связь ренты с эластичностью предложения факторов производства; классификация земельной ренты по видам; включение земельной ренты в состав издержек производства и цену производимого продукта; изменение земельной ренты в результате инвестиций в земельный участок. Обоснована необходимость продолжить исследование земельной ренты применительно к особенностям современного периода развития земельных отношений

Ключевые слова: ЗЕМЕЛЬНАЯ РЕНТА, ЗЕМЕЛЬНАЯ СОБСТВЕННОСТЬ, КАПИТАЛ, ЗАТРАТЫ ПРОИЗВОДСТВА, ЦЕНА ЗЕМЛИ, ЗЕМЕЛЬНЫЙ НАЛОГ

DOI: 10.21515/1990-4665-124-033
UDC 332.012.23:330.101.22

Economic sciences

\section{THEORY OF LAND RENTS AS \\ METHODOLOGICAL BASIS OF INSTITUTIONAL REGULATION OF LAND RELATIONS: HISTORICAL EXCURSUS}

Barsukova Galina Nikolaevna

Cand.Econ.Sci., professor of the chair of land management and land cadastre

Kuban State Agrarian University named after I.T. Trubilin, Krasnodar, Russia

There was considered the development of the theory of land rent, were shown the historical stages of formation of the institute of land rent in retrospective. There were cited the views to determine the rent-forming factors and formation of the mechanism of land rent of founders of the theory of land rent - physiocrats, U.Petti,

D.Ricardo, A.Smith, K.Marx, A.Marshall and other authors. As the result of study of various concepts, attitudes, methods of development of institutions of land ownership, land rent and land payments there was made a conclusion that the land rent presents as methodological basis of determination and development of all institutions of economic regulation of land relations; in market economics the objective rent relations must appear in land tax, in rent payment for land and price of land. There were determined the discussion regulations of modern interpretation of land rent - connection of rent with elasticity of supply of production factors; classification of land rent on types; inclusion of land rent in production costs and price of produced commodity; change of land rent in the results of investments into a land plot. There was substantiated the necessity to continue the research of land rent concerning to peculiarities of modern period of development of land relations

Keywords: LAND RENT, LAND OWNERSHIP, CAPITAL, PRODUCITON COSTS, LAND PRICE, LAND TAX

Рентные отношения в сельском хозяйстве на протяжении всей истории их развития являются предметом научных дискуссий. Несмотря на большое количество публикаций, открытым остается вопрос объективно- 
сти применения теории земельной ренты для определения земельных платежей в современной экономике. В условиях развития рыночных отношений в России, при многообразии форм собственности и многоукладности экономики, проблема формирования земельной ренты становится все более актуальной.

Одними из первых раскрыть сущность земельной ренты пытались ученые - физиократы - Ф. Кэне и А. Тюрго. Рассматривая впервые в экономической науке вопрос о происхождении прибавочной стоимости в сфере производства, они считали производительным трудом исключительно сельскохозяйственный труд. Единственным источником богатства, по мнению физиократов, являлась природа, природные свойства земли. Отсюда родилась двойственная природа земельной ренты. С одной стороны источником земельной ренты являются свойства земли, с другой - для ее получения необходим труд сельскохозяйственного работника. Земельную ренту физиократы рассматривали как всеобщую форму прибавочной стоимости, полученную за счет естественного плодородия почвы, объясняя ее происхождение производительностью земледельческого труда. Называя земледелие единственной производительной сферой, приносящей «чистый продукт», отождествляли прибавочную стоимость с рентой [10, с.26-27].

Основные положения теории земельной ренты заложили представители классической школы политэкономии, исходя из теории стоимости У. Петти, А. Смит, Д. Рикардо, К. Маркс, А. Маршалл и другие. Они непосредственно увязывали ренту и земельную собственность. А. Смит утверждал: «Как только земля становится частной собственностью, землевладелец требует долю почти со всякого продукта, который работник может взрастить на этой земле или собрать с нее» [9, с.56]. По словам К.Маркса, какова бы ни была специфическая форма ренты, всем ее типам обще то обстоятельство, что присвоение ренты есть экономическая форма, в которой реализуется земельная собственность, и что земельная рента, в свою очеhttp://ej.kubagro.ru/2016/10/pdf/33.pdf 
редь, предполагает земельную собственность, собственность определенных индивидуумов на определенные участки земли... [4, c.183].

Заложив основы трудовой теории стоимости, У. Петти рассматривал заработную плату и ренту как части стоимости, созданной трудом. Ренту У. Петти уравнивал с прибавочной стоимостью, результатом прибавочного труда. По его мнению, рента в натуральном выражении - это часть продукта, который остался после вычета заработной платы и семян. Возникновение дифференциальной ренты он объяснял различием в местоположении земельных участков и различием плодородия земли: «...Поблизости населенных мест... земли не только приносят... более высокую ренту, но и стоят большей суммы годичных рент, чем земли совершенно такого же качества, но находящиеся в более отдаленных местностях» [7, с.33]. Этим высказыванием У. Петти затронул проблему определения цены земли. Анализируя земельную ренту, подходит к определению цены земли, определяя ее как сумму годичных рент за 21 год - время совместной жизни трех поколений.

Подводя итог определения земельной ренты по У. Пети, делаем вывод:

- $\quad$ земельная рента равна продукту, произведенному на земле за вычетом издержек использованных факторов производства - труда и капитала;

- источником дохода является часть продукта, произведенного землей, отражающая вклад земли в производство продукта (чистый продукт земли);

- $\quad$ получателем земельной ренты является землевладелец [2, 7].

А. Смит, исходя из теории трудовой стоимости, доказал, что рента, как прибыль, является результатом труда. В то же время, он рассматривал земельную ренту как продукт тех сил природы, которые предоставляются собственником арендатору в порядке ссуды. Этот продукт бывает больше http://ej.kubagro.ru/2016/10/pdf/33.pdf 
или меньше, в зависимости от степени естественного или искусственно созданного плодородия земли. А. Смит в «Исследовании о природе и причинах богатства народов» утверждал: «...заработная плата, прибыль и рента являются тремя первоначальными источниками всякого дохода. А. Смит убедительно отвечает на вопрос, который впоследствии поднимают многие экономисты, и который остается актуальным и по сей день: входит ли земельная рента в цену товаров: «... работник теперь должен отдавать землевладельцу часть того, что собирает или производит его труд. Эта часть, или, что то же самое, цена этой части, составляет земельную ренту, и эта рента образует третью составную часть цены большей части товаров.» А. Смит подчеркивает, что труд определяет стоимость не только той части цен, которая приходится на заработную плату, но и тех частей, которые приходятся на ренту и прибыль [9, с. 43, 45]. В результате А. Смит характеризует ренту с трех позиций - рассматривает ее как неоплаченный труд рабочего, как результат монополии на сельскохозяйственную продукцию и как результат действия природных факторов. Обращает внимание на местоположение земельных участков: «Земельная рента изменяется не только в зависимости от плодородия земли, ... но и в зависимости от расположения ее, каково бы ни было ее плодородие. Пригодная земля дает большую ренту, чем столь же плодородная земля в отдаленной части страны» [9, c.130]. А. Смит утверждает, что доход, получающийся целиком с земли, называется рентой и достается землевладельцу.

Далее А. Смит отмечал, что часто смешивают виды дохода - прибыль с капитала или ренту от земли - когда они принадлежат одному и тому же лицу. Этот вопрос является актуальным и в настоящее время, когда мы анализируем деятельность современного фермера, который одновременно является и собственником земли и работником. «...весь излишек, остающийся после уплаты ренты и возмещения капитала, называется прибылью... заработная плата в этом случае смешивается с прибылью, так как http://ej.kubagro.ru/2016/10/pdf/33.pdf 
часть этого излишка составляет заработная плата, которую должен получить сам фермер»- так отвечает А. Смит на этот вопрос, учитывая, что фермер не является собственником земли, а всего лишь арендует землю. В данном случае доход фермера получается частью от его труда, частью от его капитала. Зато земледелец, обрабатывающий часть своего поместья, после оплаты расходов по обработке земли получает и ренту землевладельца и прибыль фермера [9, с. 46].

Если развивать эту мысль А. Смита, рассматривая современного фермера, который является собственником своей земли, то можно сделать вывод, что он получает и ренту землевладельца и прибыль фермера. Но в соответствии с современным законодательством, исходя из необходимости платы за землю, фермер часть своей ренты перераспределяет в пользу государства в форме земельного налога.

Кратко представим выводы из теории ренты А. Смита:

- $\quad$ земельная рента - это превышение стоимости продукта над валовыми издержками капитала и труда, в издержки входит и нормальная прибыль;

- рента определяется ценой продукта, а не наоборот;

- $\quad$ создает земельную ренту (или стоимость продукта) труд рабочих, земля и капитал;

- земельная рента изменяется не только в зависимости от плодородия земли, но и в зависимости от ее расположения;

- земельная рента является следствием монопольного владения землей;

- если фермер работает на собственной земле, то рента достается ему, если на арендованной, то рента достается собственнику земли.

Теория земельной ренты Д. Рикардо является наиболее известной и обсуждаемой в научной литературе. Основной работе Д. Рикардо «Начала политической экономии и налогового обложения», опубликованной в 1817 http://ej.kubagro.ru/2016/10/pdf/33.pdf 
г., предшествовало издание трактата Дж. Андерсона «Исследование природы хлебных законов» (1777г.), в котором было дано учение о ренте. В публикациях XIX в. именно Дж. Андерсона называют первым теоретиком ренты, идеи которого позднее развили Д. Рикардо, Дж. Милль, А.Маршал, Дж. Б. Кларк.

Дж. Андерсон установил две равноценные причины возникновения ренты - различное плодородие земельных участков, которые вовлекаются в производство в порядке его убывания и уменьшение прибавки продукта при увеличении интенсивности обработки земли. Позднее ренту соответственно причинам возникновения разделят на дифференциальную ренту I и дифференциальную ренту II. Затем Д. Рикардо будет анализировать обе эти причины, а Дж. Б. Кларк будет изучать только вторую причину. По сути Дж. Андерсон дал начало теории маржинализма, предвосхитив закон убывающей предельной производительности [3, 11].

В 1815 г. в Англии были опубликованы трактаты Э.Уэста, Р. Торренса, Т. Мальтуса и Д. Рикардо, в которых авторами независимо друг от друга была сформулирована теория дифференциальной ренты. Эти работы, указывая на связь между высокими ценами на зерно и вовлечением в обработку менее плодородных и менее пригодных земель, делали вывод об убывающем плодородии земли. По мнению Э. Уэста «при равных количествах работы каждое новое вложение в сельское хозяйство в действительности дает все меньшую отдачу. Эти авторы считали, что в сельском хозяйстве отдача уменьшается, несмотря на изменения в технологии: «...по мере совершенствования методов труд в земледелии становится менее производительным...[ что] более чем съедает эффект от механизации и разделения труда в сельском хозяйстве» [1, с.71].

Следует отметить, что это утверждение было подтверждено в последующие десятилетия интенсивного развития сельского хозяйства, однако некоторые авторы считают его спорным и в настоящее время.

http://ej.kubagro.ru/2016/10/pdf/33.pdf 
Все четыре автора предполагали, что закон убывающей отдачи характеризует не столько экстенсивную, сколько интенсивную обработку земли и сделали вывод, что цена продукции регулируется наихудшими условиями производства продукции, следовательно рента - это излишки продукции фермера, работающего в предельных условиях, над затратами его труда и капитала. Цена определяется предельными издержками фермера, работающего в предельных условиях, которые выше его средних издержек. Этот излишек является рентой и уплачивается землевладельцу [1, c.73].

Т. Мальтус увидел в ренте то важное качество, что при неодинаковом плодородии земель вложенные в них капиталы по необходимости дают неодинаковую прибыль и эта разница (difference) между прибылью на земле средней плодородности и более плодородной составляет специальную категорию ренты - дифференциальную [10, с. 120-124].

Д. Рикардо в разработке теории земельной ренты отбросит всякое участие природы в создании ренты. По мнению Д. Рикардо рента появляется тогда, когда рост населения принуждает разрабатывать земли низшего качества или хуже расположенные. Рента образуется от редкости хороших земель и необходимости осваивать худшие по качеству земли. «Рента - создание ценности, а не создание богатств» [10, с.126-127].

Это утверждение нельзя считать полным объяснением ренты, скорее редкость угодных для обработки земель - это условие появления ренты. При этом ценность определяется стоимостью производства, трудом на участке земли с самыми неблагоприятными условиями. Он считает, что есть определенные категории земель, которые не дают ренты, а только возмещает расходы по обработке.

Д. Рикардо развил учение о ренте, опираясь на трудовую теорию стоимости. Он рассматривал ренту как обособившуюся часть прибыли, в то время как прибылью называл избыток стоимости над заработной плаhttp://ej.kubagro.ru/2016/10/pdf/33.pdf 
той. Рента образуется в соответствии с законом стоимости, создается трудом, её не следует смешивать с прибылью и процентом на капитал. Единственным основанием земельной ренты считал собственность на землю. Он обратил внимание на особенности земли - её ограниченность и неоднородность по плодородию и местоположению. Можно сказать, что Д. Рикардо определил рентообразующие факторы: разный природный потенциал участков (плодородие) и разную удаленность этих участков от рынков реализации продукции [2, с.141].

По мнению многих современных авторов концепция Д. Рикардо о ренте сохраняет свою актуальность и в настоящее время. Д. Рикардо считал, что «...рента всегда платится за пользование землей только потому, что количество земли не беспредельно, а качество - неодинаково...» $[8$, c.112]. С ростом численности населения обработке начинают подвергаться новые участки земли, худшие по своему качеству и расположению, затратами труда на которых определяется стоимость сельскохозяйственных продуктов.

Анализируя способ присвоения ренты, Д. Риккардо, по сути, доказывает, что рента не существует при абсолютно эластичном предложении фактора производства - земли: «... никто не станет платить за пользование землей, раз налицо масса еще не обращенной в собственность земли, которою поэтому может располагать всякий, кто захочет обрабатывать её». Д. Рикардо рассматривает ситуацию, когда собственник на землю есть, а ренты нет. Это возможно, когда возделывается и находится в собственности тех, кто возделывает, незначительная часть земли. Примером может служить формирование земельной собственности в Киевской Руси, и позднее - в Русском централизованном государстве, когда крестьянская община имела, по сути, освоенные земельные участки в собственности, но это были «черные земли» до той поры, (в ряде районов - до 17-18 вв.) пока не были обложены данью, налогом в виде земельной ренты. 
Анализируя теорию земельной ренты Д. Риккардо, можно сделать следующие выводы:

- рента образуется в соответствии с законом стоимости, создается трудом как обособившаяся часть прибыли;

- $\quad$ в производстве участвуют все три фактора - труд, земля, капитал;

- $\quad$ ренту не следует смешивать с прибылью и процентом на капитал;

- рентообразующими факторами являются разный природный потенциал участков (плодородие) и разная удаленность этих участков от рынков реализации продукции;

- условиями образования ренты является редкость хороших земель и обращение земли в собственность;

- рента не входит в стоимость сельхозпродуктов, ликвидация ренты не обеспечит снижение цены продуктов;

- рента - это доля продукта, которая уплачивается землевладельцу за «пользование первоначальными и неразрушимыми силами почвы».

Современные авторы считают, что учение Д. Риккардо о ренте сохранило свое значение и в настоящее время, хотя и с большими поправками.

Позднее Дж. С. Милль, которого считают завершителем классической политической экономики, в своем главном труде «Основы политической экономии» (1848 г.) рассматривает теорию ренты с позиций Д. Риккардо. Принимая его положение о рентообразующих факторах, видит в ренте компенсацию, уплачиваемую за пользование землей [6, с. 150]. При этом Дж. С. Миль уточняет, что в зависимости от форм использования земельного участка он может либо обеспечивать ренту, либо, наоборот, потребует издержек, исключающих этот доход.

http://ej.kubagro.ru/2016/10/pdf/33.pdf 
Дж. С. Милль отмечает, что и наихудшая земля может также давать ренту, причина этой ренты заключается в том, что «продукт в действительности имеет ценность редкости» [10, с. 423]. Дж. С. Милль определяет ренту с любого участка земли как «... разницу между полученным с этого участка продуктом и тем доходом, который принес бы тот же самый капитал, будь он использован на возделывание самой худшей из обрабатываемых земель». По-новому Дж. С. Милль рассматривает капитал, вложенный в улучшение земли «... доход на такой капитал полностью утрачивает характер прибыли и подчинен принципам ренты» [6, с.155, 167].

Дж. С. Милль первым понял, что рента, получаемая на участке земли, который используется в какой-либо одной форме, при другом использовании участка превращается в издержки, которые надо оплачивать. С точки зрения фирмы, вкладывающей средства в использование какоголибо фактора производства, рента является частью издержек производства. С точки зрения общества рента определяется ценой и может быть обложена налогами Стюарт Милль обобщил концепцию ренты на все блага и факторы производства с неэластичным предложением. В этих случаях цены определяются предельными издержками. С одной стороны, «цена, уплаченная за дифференциальные преимущества в производстве товара, не может входить в общие издержки производства товара». А с другой стороны, нельзя не признать, что рента влияет на цену, являясь затратами производства, в том случае, когда фактор является предметом альтернативного использования [1, с. 180].

К. Маркс, анализируя земельную ренту, дает определение цены производства - цена производства товара равняется его издержкам производства плюс средняя прибыль. Средняя прибыль по Марксу это не усредненная по предприятиям прибыль, а ее нормальная (минимально приемлемая) величина. Цена производства по Марксу есть экономические издержки производства. В знаменитой формуле стоимости товара К. Маркс не http://ej.kubagro.ru/2016/10/pdf/33.pdf 
учитывает издержки использования земли и процент на постоянный капитал, т.е. не учитывает альтернативные издержки земли как капитала. Следует отметить, что эти издержки в то время не были известны. Альтернативные (или временные) издержки - это издержки упущенной выгоды, упущенных возможностей. По мнению современных авторов, альтернативными можно считать рыночные цены факторов производства.

Английская политическая экономия, проникнутая идеями Риккардо, и поныне придерживается дифференциальной ренты. Ряд экономистов пришли к выводу, что везде, где цена какого-нибудь продукта приобретает ценность редкости и превышает стоимость производства по ряду причин, получается рента для продавца этого продукта. Этот вывод независим от закона убывающего плодородия или разного плодородия земель [10, с. 424].

Шефле в 1867 г. обосновывая ренту вообще и земельную ренту в частности, определял их как премии, выдаваемые тому, кто умеет наиболее эффективно использовать или свои способности, или капиталы, или земли. [10, с.534]. При этом он подчеркивает особенность земли, отличающую ее от других капиталов - неспособность ее к перемещению или размножению.

В 1872 К. Менгер в «Основаниях политической экономии» ввел теорию ренты в общую теорию цен, утверждая, что «услуги земли в отношении ценности их подчиняются тем же общим законам, что и услуги машин, орудий, жилых помещений и фабрик или всех других экономических благ, какова бы ни была их природа [10, с. 425].

А. Маршал разделяет эту точку зрения: «... переходя от свободных даров природы к продолжительным мелиорациям почвы, затем к менее продолжительным, от них к сооружениям фирмы или завода, от этих последних к паровым машинам и т.д. и, наконец, к менее прочным и быстрее производящим орудиям, мы находим целый беспрерывный ряд (рент)». В http://ej.kubagro.ru/2016/10/pdf/33.pdf 
своем труде «Принципы политической экономии» А. Маршалл делает вывод, что рента - платеж за любой невоспроизводимый ресурс. Определяя отличие ренты, обусловленной редкостью, от дифференциальной ренты, Маршал считает, что все виды ренты являются рентами, обусловленными редкостью, и все виды ренты являются дифференциальными рентами.

$\mathrm{B}$ «Принципах политической экономии» А. Маршалл подчеркивает мысль экономистов, что с общественной точки зрения земля не находится в одинаковом положении с другими средствами производства, которые человек может увеличивать беспредельно, еще раз подчеркивает особый характер земли, как производительного фактора [5 с. 243]..

По мнению А. Маршалла экономисты могут применять термин «рента»в тех случаях, когда рассматривается доход с позиции индивидуального предпринимателя, вкладывая в это понятие плату за временное использование имуществом. Анализируя проблему убывающей предельной отдачи, А. Маршалл приходит к выводу, что отдача от дополнительного вложения капитала и труда рано или поздно уменьшается: ... при любом будущем улучшении агротехники непрерывный рост приложения капитала и труда к земле должен в конечном счете привести к уменьшению дополнительного продукта...». [5, с. 223].

Доход, вызванный «улучшениями земли, произведенными человеком», следует считать прибылью на капитал. Платеж за использование земли со всеми улучшениями почвы - это и есть земельная рента. Рента зависит не только от свойств почвы, но и от всех изменений, происходящих в экономике. Прокладка дорог, изменение цен труда и капитала, изменение цен всех благ, которыми пользуются люди и всех капитальных благ, изменение доходов во всех отраслях - все влияет на величину ренты. Земельная рента любого участка зависит от состояния всей экономики. В любой момент времени состояние экономики является фиксированным: дороги построены, цены определились, и значит, определилась рента. А. http://ej.kubagro.ru/2016/10/pdf/33.pdf 
Маршалл рассматривает вариант, когда договор аренды земли заключается на длительный срок, в течение которого могут измениться условия производства и величина ренты. Необходимость предвидеть изменение условий производства ренты, является проблемой и для предпринимателей, и для землевладельцев [11].

Взгляд А. Маршалла на ренту позволяет сделать следующие выводы:

- земельная рента первая подверглась анализу в экономической науке и поэтому наиболее изучена;

- $\quad$ А. Маршалл не видит принципиальной разницы между дифференциальной рентой и рентой, обусловленной редкостью;

- эффективности вложений дополнительной (предельной) единицы денег во все факторы производства должны быть равны между собой.

В соответствии с теорией Д. Риккардо, земельная рента как вознаграждение природного и невоспроизводимого фактора производства должна подлежать налогообложению. Первым сформулировал эту мысль Дж. Миль.

Американский журналист Г. Джордж в книге «Прогресс и бедность» (1879) определил ренту не просто как доход, подходящий для обложения налогом, а как источник социальных зол. Был сделан вывод уничтожив ренту, вы уничтожите бедность, неравенство и даже кризисы. Единого налога на землю будет достаточно для покрытия всех государственных расходов. Он предложил конфискацию всех рентных доходов, считая, что это сможет устранить бедность и экономические кризисы. При этом он имел ввиду налогообложение чистой земельной ренты за вычетом доходов от улучшения качества земельных участков, т.е. приращение дохода от повышения цены земли [1, с. 77-78, 10, с.429-432]. 
Из теории земельной ренты Д. Риккардо был сделан вывод о том, что земельная рента является нетрудовым доходом, следовательно, явлением незаконным. Вскоре появились предложения конфисковать ренту в пользу государства (Джеймс Милль, Стюарт Милль, сенсимонисты). Современник Д. Риккардо экономист Дж. Милль предложил конфисковать ренту и тем самым положил начало учению о национализации земли [10, с. 129].

Все последующие социальные теории, все системы национализации земли, все проекты социализации ренты покоятся на теории Д. Риккардо [10, с. 417], ибо земельная рента - это незаработанный доход, доход, не узаконенный трудом.

Последователи Д. Риккардо, представители предельной полезности - Л. Вальрас и П. Х. Уикстид выступали за национализацию земли с полной компенсацией. Предполагалось компенсировать владельцев облигациями, выплачивая проценты и погашение займа из будущих рентных доходов.

Под руководством идей Г. Джорджа в конце XIX начале XX вв. в Америке и Европе возникло движение за единый налог на землю, изымающий земельную ренту в пользу общества. А. Маршалл, возражал против такого «единого налога», считал, что все факторы экономического процесса могут получать кратковременную ренту, которую можно рассматривать как стимулирующие платежи, которые поощряют использование плодородных и потому дефицитных участков» [1, с. 78-79].

В России противником частной собственности на землю и сторонником идей Г. Джорджа был Л. Н. Толстой. Он высказывался за полное изъятие ренты у собственника земли: «Всякий пусть платит с земли своей столько, сколько она может принести аренды (ренты) в том году, в котором он владеет ею». Деньги, собираемые с земли, предлагалось использо- 
вать в общих интересах, заменив земельным налогом все прочие налоги и сборы [12].

В результате исследования различных концепций, взглядов, методик на теории развития институтов земельной собственности, земельной ренты и земельных платежей сделаны следующие выводы:

- земельная рента выступает как экономическая форма реализации земельной собственности;

- $\quad$ определение ренты дает разные трактовые связи ренты с эластичностью предложения факторов. Этот вопрос остается открытым;

- дискуссионным в течение многих десятилетий остаются вопросы классификации земельной ренты по видам, включения земельной ренты в состав издержек производства и в цену производимого продукта;

- теория земельной ренты представляет собой методологическую основу определения и развития по сути всех институтов экономического регулирования земельных отношений;

- исследование особенностей формирования земельной ренты в современных условиях трансформации земельных отношений представляет большой практический интерес и должно быть продолжено;

- в рыночной экономике объективные рентные отношения, прежде всего, должны проявляться в земельном налоге, в арендной плате за землю, цене земли;

- обоснованное перераспределение земельной ренты должно стимулировать развитие сельскохозяйственного производства, способствовать снижению социальной напряженности в обществе.

\section{Список литературы:}

1. Блауг, М. Экономическая мысль в ретроспективе / М. Блауг. Пер. с англ. 4-е изд. - М: - Дело ЛТД. - 1994. - 720 с. 
2. История экономических учений. Курс лекций. Под ред. Заррина П.И., Поспелова Н.Г., Цага В.Ф. М.: Высшая школа. - 1963. - 684 с.

3. Кларк, Дж. Б. Распределение богатства / Дж. Б.М. Кларк. - М: Экономика, 1992. $-446 \mathrm{c}$.

4. Маркс, К. Капитал. Критика политической экономии / К. Маркс, Ф. Энгельс. т.3 ч.2. Соч. т. 25. - М.: Госуд. Издательство политической литературы. - 1962. $551 \mathrm{c}$.

5. Маршалл, А. Принципы политической экономии / А. Маршалл: В 3-х т. Т. I. М: Прогресс, 1983. - 415 с.

6. Милль, Дж.С. Основы политической экономии / Дж. С. Милль. Т.2 М: Прогресс, 1980.

7. Петти, У. Трактат о налогах и сборах / У. Петти // Шедевры мировой экономической мысли. У. Петти В 2т.Т.2 - Петрокоммерц, 1993. - 320 с.

8. Рикардо, Д. Начала политической экономии и налогового обложения / Шедевры мировой экономической мысли. Д. Рикардо В 2т. Т.2 - Петрокоммерц, 1993 $320 \mathrm{c}$.

9. Смит, А. Исследования о природе и причинах богатства народов / Шедевры мировой экономической мысли. А. Смит В 2т.Т.2 - Петрокоммерц, $1993-320$ с.

10. Жид, Ш. История экономических учений / Ш. Жид, Ш. Рист. - М.: Экономическое наследие, 1995. - 544 с.

11. http://mbs-renta.narod.ru/ Малышев . Общая теория ренты

12. http://az.lib.ru/t/tolstoj_lew_nikolaewich/text_1390.shtm

\section{References:}

1. Blaug, M. Jekonomicheskaja mysl' v retrospektive / M. Blaug. Per. s angl. 4-e izd. - M: - Delo LTD. - 1994. - 720 s.

2. Istorija jekonomicheskih uchenij. Kurs lekcij. Pod red. Zarrina P.I., Pospelova N.G., Caga V.F. M.: Vysshaja shkola. - 1963. - 684 s.

3. Klark, Dzh. B. Raspredelenie bogatstva / Dzh. B.M. Klark. - M: Jekonomika, 1992. $-446 \mathrm{~s}$.

4. Marks, K. Kapital. Kritika politicheskoj jekonomii / K. Marks, F. Jen-gel's. t.3 ch.2. Soch. t. 25. - M.: Gosud. Izdatel'stvo politicheskoj literatury. - 1962. - $551 \mathrm{~s}$.

5. Marshall, A. Principy politicheskoj jekonomii / A. Marshall: V 3-h t. T. I. M: Progress, 1983. $-415 \mathrm{~s}$. 1980.

6. Mill', Dzh.S. Osnovy politicheskoj jekonomii / Dzh. S. Mill'. T.2 M: Progress,

7. Petti, U. Traktat o nalogah i sborah / U. Petti // Shedevry mirovoj jekonomicheskoj mysli. U. Petti V 2t.T.2 - Petrokommerc, 1993. - 320 s.

8. Rikardo, D. Nachala politicheskoj jekonomii i nalogovogo oblozhenija / Shedevry mirovoj jekonomicheskoj mysli. D. Rikardo V 2t. T.2 - Petrokommerc, 1993 - 320 s.

9. Smit, A. Issledovanija o prirode i prichinah bogatstva narodov / Shedevry mirovoj jekonomicheskoj mysli. A. Smit V 2t.T.2 - Petrokommerc, 1993 - 320 s.

10. Zhid, Sh. Istorija jekonomicheskih uchenij / Sh. Zhid, Sh. Rist. - M.: Jekonomicheskoe nasledie, 1995. - $544 \mathrm{~s}$.

11. http://mbs-renta.narod.ru/ Malyshev . Obshhaja

12. http://az.lib.ru/t/tolstoj_lew_nikolaewich/text_1390.shtm 